\title{
Heat transfer efficiency improvement in high-pressure metal hydride by modeling approach
}

\author{
Nur Aisyah Jalalludin ${ }^{a^{*}}$, Noboru Katayama ${ }^{\mathrm{b}}$, Sumio Kogoshi ${ }^{\mathrm{b}}$, Goro Fujita ${ }^{\mathrm{a}}$ \\ ${ }^{a}$ Department of Electrical Engineering, Shibaura Institute of Technology, 3-7-5 Toyosu, Koto-ku, Tokyo 135-8548 Japan \\ ${ }^{b}$ Department of Electrical Engineering, Tokyo University of Science, 2641 Yamazaki, Noda-shi, Chiba-ken 278-8510 Japan
}

\begin{abstract}
High-Pressure Metal Hydride (HPMH) for hydrogen storage system is known to have a high volumetric capacity compared to other storage materials. However, a vast amount of heat is generated during refueling of hydrogen in HPMH, where the heat will slow down or stop the absorption of hydrogen into the storage tank and causes a slow refueling time. Aside from heat generation, usage of heat exchangers for dissipation of heat in HPMH increases the weight and volume of the storage tank. In this paper, a prototype of heat exchanger design from a previous paper is revised, and a new prototype is proposed to improve the heat dissipation efficiency while achieving minimal space of heat exchanger in the system. Three prototypes of heat exchanger design are proposed, and the time taken for complete hydrogen absorption and the required space for heat exchanger are compared with the previous model. From the simulation results, two of the proposed models are proven to achieve a faster hydrogen absorption rate with a lower space area of heat exchangers.
\end{abstract}

Keywords: High-pressure metal hydride, heat exchanger, hydrogen storage, hydriding

\section{Introduction}

In recent years, zero-emission technologies and usage of renewable energy sources have acquired a lot of attention. Fossil fuel depletion along with environmental pollution has increased public awareness regarding the need of new alternative energy sources. One of the alternative energy sources is hydrogen, which has high energy content per unit mass. In transportation, hydrogen is used to generate electricity in fuel cell vehicles through reaction with oxygen. In order to supply hydrogen to the fuel cell, a safe, durable hydrogen storage tank with high volumetric and gravimetric capacity is required for a highlyefficient fuel cell vehicle. To travel a distance of about 300 miles, a fuel cell vehicle needs to be fueled with $5 \mathrm{~kg}$ of hydrogen [1]. Methods that are mainly used for hydrogen storage are pressurization, liquefaction and storage in the form of solid-state hydrogen in metal hydride. Apart from maintaining a compact-sized tank and lightweight system, the time taken to refuel the tank with $5 \mathrm{~kg}$ of hydrogen must be short. To store hydrogen in a metal hydride tank, a heat exchanger is required to dissipate heat produced by metal hydride during absorption of hydrogen. Faster heat dissipation will result in a faster refueling process. Therefore, a heat exchanger that can aid a fast refueling process with minimal weight and volume is needed in order to meet the requirements of an efficient system.

According to the targets set by Department of Energy (DOE) for onboard hydrogen storage system, the ultimate level of hydrogen refueling time is 2.5 minutes, while the gravimetric and volumetric capacity of the system is $2.5 \mathrm{kWh} / \mathrm{kg}$ and $2.3 \mathrm{kWh} / \mathrm{L}$ respectively [2]. To reach these targets, various simulation and experimental methods have been investigated using distinctive hydrogen storage materials and heat exchanger designs [3-8]. In a previous work done by Milan Visaria et al. [3], a two-dimensional prototype of heat exchanger in a $\mathrm{Ti}_{1.1} \mathrm{CrMn}$ metal hydride tank is proposed, where the temperature, reaction

\footnotetext{
* Manuscript received June 15, 2013, revised July 19, 2013.

Corresponding author. Tel.: +8180-4472-2507; E-mail address: ma13065@ shibaura-it.ac.jp.
} 
completion, and volumetric heat generation over time is recorded. The heat exchanger is constructed to occupy $29 \%$ of the tank, but the total weight and volume of the tank with different prototypes are not taken into consideration. G. Mohan et al. simulated a system using air-cooled heat exchanger with plate fins [4] while emphasizing on the system's total weight. Additionally, simulation of a three-dimensional model has also been proposed [5] inclusive of the experimental results by using aluminum foam with the heat exchanger.

The main aim of this paper is to create a highly efficient heat exchanger with minimal space area in metal hydride tank while maximizing the rate of reaction in 5 minutes time. In this paper, the 2dimensional prototype proposed by Milan Visaria et al. [3] is constructed using the exact measurements, and three new prototypes are designed using COMSOL Multi-physics. Rate of hydrogen absorption in $\mathrm{Ti}_{1.1} \mathrm{CrMn}$ metal hydride is recorded with different cross-sectional areas of heat exchanger plates.

\section{Simulation Methodology}

Two dimensional heat exchanger prototypes are designed where one of the prototypes is constructed using the exact measurement and parameters used in [3]. The heat exchanger prototypes designed using a cross-sectional part of the cylindrical tank, as shown in Fig. 1. The cross-sectional areas consist of domains of aluminum heat exchanger plate, $\mathrm{Ti}_{1.1} \mathrm{CrMn}$ metal hydride, and liquid coolant tubes.

To increase the capacity of hydrogen to be stored in the hydride tank, the thickness of the metal hydride must be maximized. Apart from that, the total cross-sectional area of the heat exchanger plate must be minimized to in order to achieve a lightweight and compact system while maintaining efficient heat dissipation. The addition of fins on the heat exchanger results in a better heat dissipation [6], which leads to a shorter refueling time. Thus, plate fins are required for an efficient heat exchanger. In this paper, cross-sectional design of heat exchangers consisting of four coolant tubes and plate fins are proposed, and for simulation validation, the prototype in [3] (Model 1) is also constructed (Fig. 1(a)). The thickness of the plate fins must be minimized to reduce the space area occupied by the heat exchanger, and at the same time, the number of fins must be enough to ensure an equal absorption of heat throughout the metal hydride. The prototypes are designed and simulated using the Heat Transfer Module in COMSOL Multiphysics, and the rate of reaction is recorded for each prototype while comparing with the previous prototype.

In order to improve the heat dissipation efficiency of the previous model and increase the areas occupied with metal hydride, prototypes named as Model 2 (Fig. 1 (b)), Model 3 (Fig. 1 (c)) and Model 4 (Fig. 1 (d)) are created. The parts with insufficient cooling effect is added with more plate fins, and instead of using two coolant tubes as in the previous model, four coolant tubes are used to enhance more heat transfer to the coolant. As shown in Fig. 1 (b), the plate fin is constructed to be in a circular shape, but with the same thickness of fins with Model 1 . Then, the thickness of the plate fin is slightly increased in Model 3 to add the cooling effect. In Model 4, the number of plate fins is increased while reducing the thickness in order to maintain the cooling effect without increasing the area occupied by the heat exchanger plate.

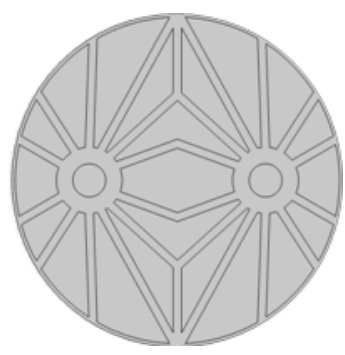

(a)

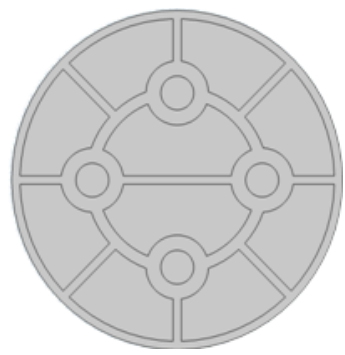

(b)

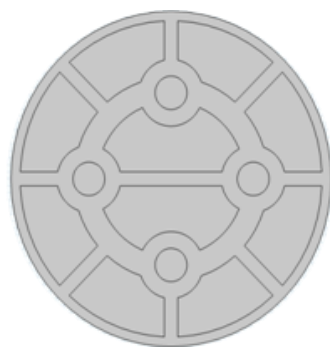

(c)

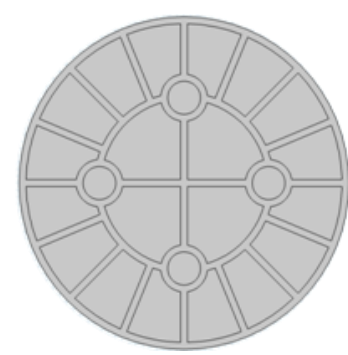

(d)

Fig. 1. Cross-sectional part of cylindrical metal hydride tank with heat exchanger plate and coolant tubes. 


\section{Modeling Equations}

Heat conduction, heat insulation and heat flux equations are applied to the constructed prototypes where the parameters for the operating conditions and properties of $\mathrm{Ti}_{1.1} \mathrm{CrMn}$ metal hydride are referred to the numerical values used in [3].

\subsection{Heat conduction}

The exterior boundary of the tank is assumed to be an adiabatic boundary, where heat diffusion does not occur. In other words, the heat produced during hydriding process is assumed to be completely dissipated by the heat exchanger. Heat diffusion equations for metal hydride and aluminum are given by

$$
\begin{aligned}
& k_{M H}\left(\frac{\partial^{2} T}{\partial x^{2}}+\frac{\partial^{2} T}{\partial y^{2}}\right)+q^{\prime \prime \prime}=\rho_{M H} c_{p, M H} \frac{\partial T}{\partial t} \\
& k_{A l}\left(\frac{\partial^{2} T}{\partial x^{2}}+\frac{\partial^{2} T}{\partial y^{2}}\right)=\rho_{A l} c_{p, A l} \frac{\partial T}{\partial t}
\end{aligned}
$$

$k_{M H, A l}, \rho_{M H, A l}, c_{p, M H, A l}$ represents the thermal conductivity, density, and specific heat of metal hydride and aluminum respectively, while $q^{\prime \prime \prime}$ is the total volumetric heat produced during hydriding reaction and pressurization in metal hydride.

$$
q^{\prime \prime \prime}=\frac{d F}{d t} \frac{(w t \%) \rho_{M H}}{M W_{H_{2}}} \Delta H_{r}+\varphi \frac{d P}{d t}
$$

$F$ is the rate of reaction completion, $M W_{H 2}$ is the molecular weight of hydrogen, $\Delta H_{r}$ is the enthalpy of reaction, $\varphi$ is the porosity of metal hydride, and $P$ represents pressure of the tank. The reaction rate, $F$ is derived from the equation of hydrogen mass absorbed per unit time and volume [9].

$$
\frac{d F}{d t}=C_{a} \exp \left(\frac{-E_{a}}{R T}\right) \ln \left(\frac{P}{P_{e q}}\right)(1-F)
$$

where $C_{a}$ is the hydriding constant, $E_{a}$ is the activation energy, $R$ is the universal gas constant and $P_{e q}$ is the equilibrium pressure. $F$ reaches the value of 1 when hydrogen is fully absorbed at maximum capacity of the metal hydride. At $0 \mathrm{~s}$, the tank pressure, $P$ is set at $1 \mathrm{bar}$, and is increased linearly to 300 bar until $60 \mathrm{~s}$. The pressure is then maintained at 300 bar after $60 \mathrm{~s}$. The equilibrium pressure, $P_{e q}$ is represented by the following equation.

$$
P_{e q}=P_{o} \exp \left(\frac{\Delta H_{r}}{R T}-\frac{\Delta S}{R}\right)
$$

$P_{o}$ and $\Delta S$ are the ambient pressure and entropy of reaction respectively. Equations (1), (3), (4) and (5) are applied in the simulation for the metal hydride domain, and equation (2) is applied to the heat exchanger domain as shown in Fig. 2 and Fig. 3 respectively.

\subsection{Heat insulation}

To ensure no heat diffusion to the exterior part of the tank, heat insulation boundary is assumed on the outer part of the tank, as shown in Fig. 4. Specifically, the temperature gradient across the outer boundary of the heat exchanger is zero due to the absence of heat flow rate. This condition can be represented by

$$
n(k \nabla T)=0
$$




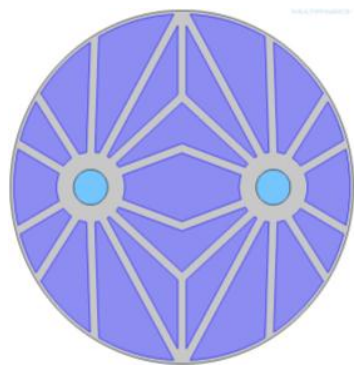

(a)

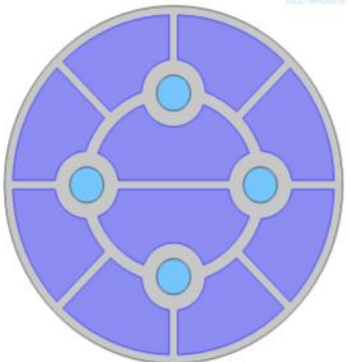

(b)

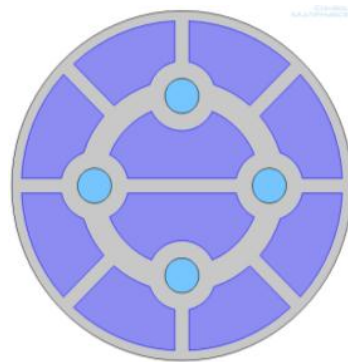

(c)

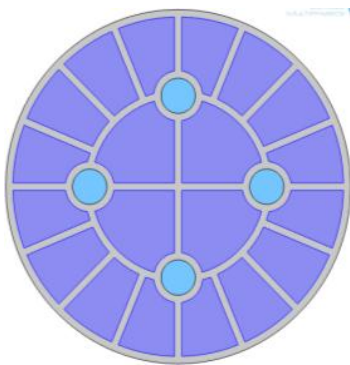

(d)

Metal hydride domain

Coolant tube domain

Fig. 2. Metal hydride domains with heat conduction equations.

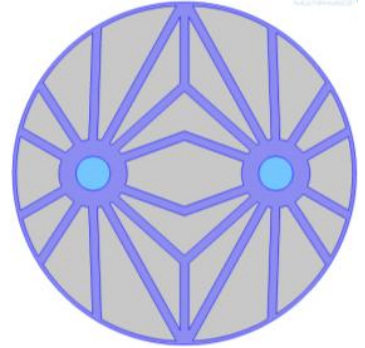

(a)

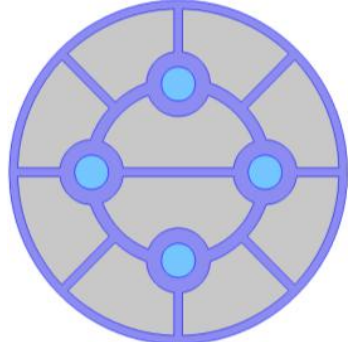

(b)

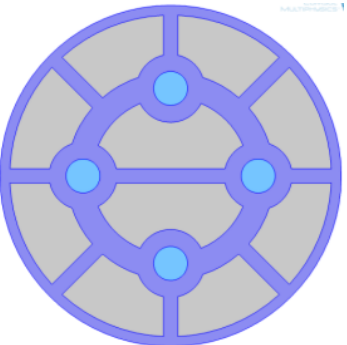

(c)

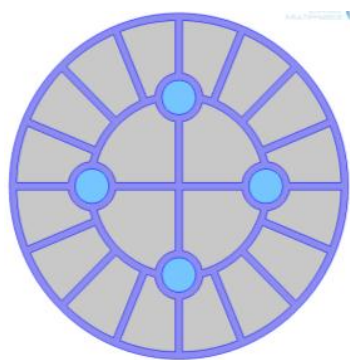

(d)

Heat exchanger plate (plate fins) domain

Fig. 3. Heat exchanger plate domain with heat diffusion equation.

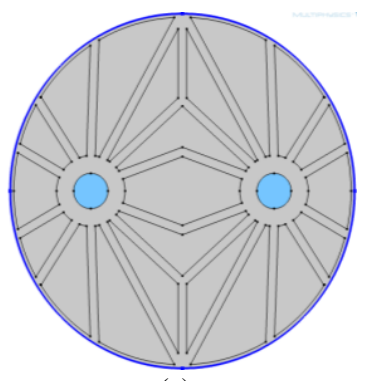

(a)

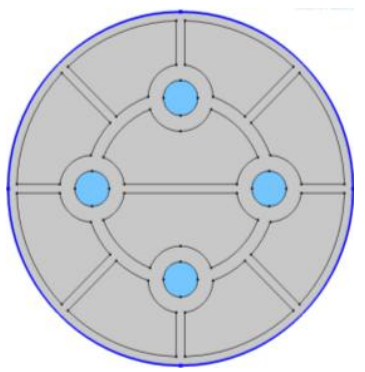

(b)

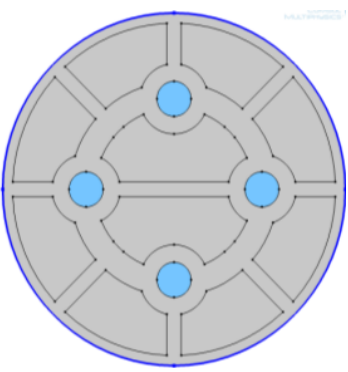

(c)

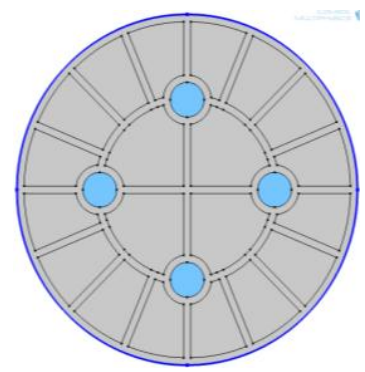

(d)

Heat insulation boundary

Fig. 4. Heat insulation boundaries with no heat transfer.

\subsection{Heat Flux}

To create a heat transfer between the metal hydride and the heat exchanger, as well as the coolant domain and the heat exchanger domain, heat flux equation is applied on those boundaries. Heat flux, $q_{o}$ is defined by the coefficient of convective heat transfer coefficient, $h$ and the temperature difference of the boundaries.

$$
q_{o}=h\left(T_{\text {ext }}-T\right)
$$

As the heat transfer between metal hydride and heat exchanger plate is bidirectional, the external temperature, $T_{e x t}$ of metal hydride is the temperature of the heat exchanger plate at that time and vice versa. The coolant temperature is assumed to be constant at $273.15 \mathrm{~K}$, which is the $T_{e x t}$ of the heat exchanger during the heat transfer between coolant and the heat exchanger. Basically, the heat flux equations are divided into two boundaries, which are 
- Case 1: Metal hydride and plate fins boundary (Fig. 5)

- Case 2: Plate fins and coolant tube boundary (Fig. 6)

For case 1, the heat transfer coefficient $h$ is the inverse of contact resistance, $R_{t c}$, where the value of $R_{t c}$ used is $2000 \mathrm{~mm}^{2} \mathrm{~K} / \mathrm{W}$ [3]. In case 2, by referring to the coolant's properties in [3], the value of $h$ used in this simulation is $2500 \mathrm{~W} / \mathrm{m}^{2} \mathrm{~K}$. The initial temperature of both heat exchanger plate and metal hydride are assumed at room temperature, which is approximately $293.15 \mathrm{~K}$.

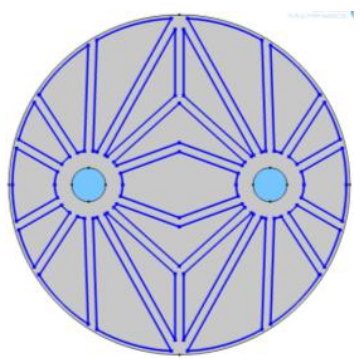

(a)

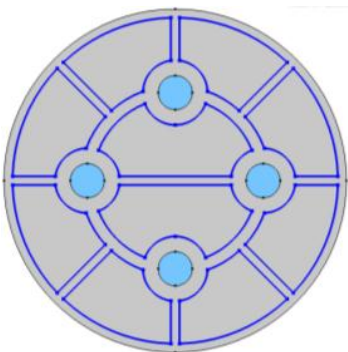

(b)

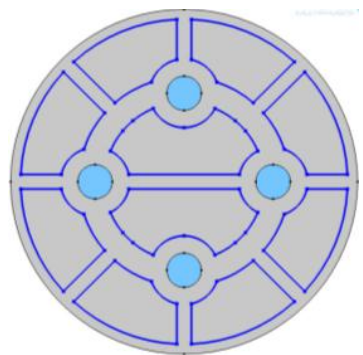

(c)

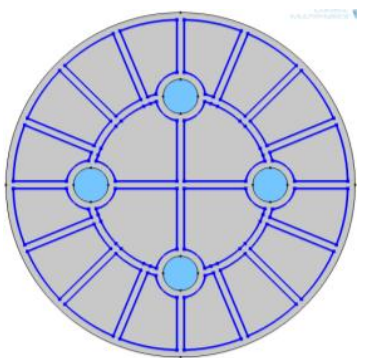

(d)

Heat flux boundary

Fig. 5. Heat flux boundaries in between metal hydride and heat exchanger domains.

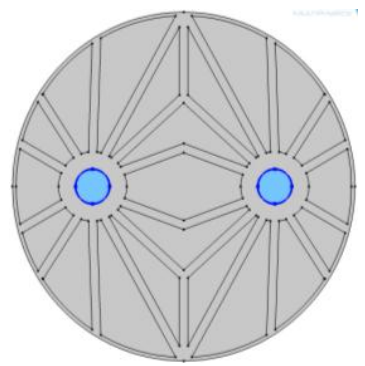

(a)

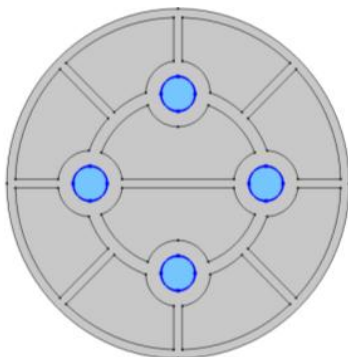

(b)

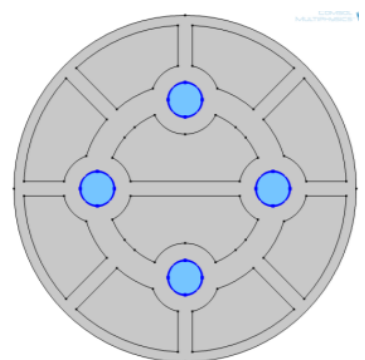

(c)

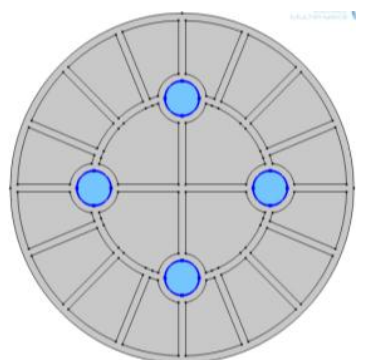

(d)

Heat flux boundary

Fig. 6. Heat flux boundaries between coolant and heat exchanger domains.

\section{Results and Discussion}

\subsection{Heat exchanger surface area reduction}

One of the solutions to reduce the weight and volume of a hydrogen storage system is minimizing the surface area of the heat exchanger plate, but at the same time the heat exchanger must be able to maintain a good heat dissipation efficiency. To fulfill these requirements, the thickness and the number of the plate fins must be adjusted so that hydrogen refueling can be completed at a short period of time even with a lightweight and compact system. If the plate fins are too thick, or the number of plate fins is too large, heat dissipation will occur faster but the system's weight is affected, and vice-versa. Additionally, the total surface area of metal hydride needs to be maximized to increase the hydrogen capacity that can be stored.

The cross-sectional diameter of the tank and the surface area of the coolant tube is the same for every prototype, but the distinction points of the proposed models and the previous model are the number of coolant tubes and plate fin design. The surface area of the heat exchanger plates and metal hydride are calculated by integrating the domains, and the results are compared in Table 1. It can be seen that Model 4 has the highest total surface area of metal hydride and the lowest total surface area of heat exchanger plate. Therefore, it is assumed that Model 4 has the highest hydrogen storage capacity with the lowest heat exchanger volume occupying the tank. 
Table 1. The total surface area of metal hydride and heat exchanger plate of the previous and proposed prototypes

\begin{tabular}{lcc}
\hline \hline Prototype & \multicolumn{2}{c}{ Total surface area $\left(\mathrm{m}^{2}\right)$} \\
\cline { 2 - 3 } & Metal hydride & Heat exchanger $\left(\mathrm{m}^{2}\right)$ \\
\hline Model 1 & 0.00477 & 0.00225 \\
Model 2 & 0.0047 & 0.00196 \\
Model 3 & 0.00408 & 0.0028 \\
Model 4 & 0.00507 & 0.00181 \\
\hline \hline
\end{tabular}

\subsection{Reaction rate distribution}

From the simulation, the reaction rate for each prototype is compared as shown in Fig. 6. The results are taken at $300 \mathrm{~s}$ since the target for hydrogen fill time in this paper is 5 minutes. The color contour represents the change for each parameter in the cross-sectional part of the metal hydride, where a brighter color contour represent areas with high rate of heat transfer.

At $60 \mathrm{~s}$ and below, the pressure is maintained at 300 bars and therefore the heat of pressurization is maintained at a constant value at $300 \mathrm{~s}$, while the heat of reaction depends on the equilibrium pressure of the system at that time. It can be observed that the reaction rate of Model 3 and 4 is higher than Model 2 and Model 1, where the reaction of hydrogen and $\mathrm{Ti}_{1.1} \mathrm{CrMn}$ in Model 3 and 4 are nearly completed, but several parts in Model 1 and 2 have a reaction rate of 0.5 , which is still far from 1 . Next, the change in average rate of reaction with time is represented in a graph, as shown in Fig. 7. Overall, the reaction rate in the proposed prototypes is higher than the previous model, and it can be concluded that a shorter time for a complete hydrogen refueling process can be achieved.

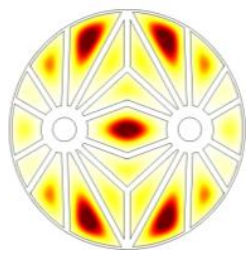

(i)

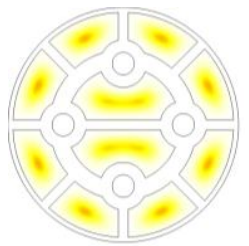

(iii)

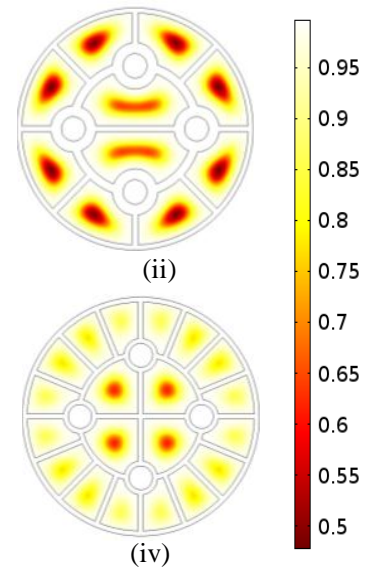

(a)

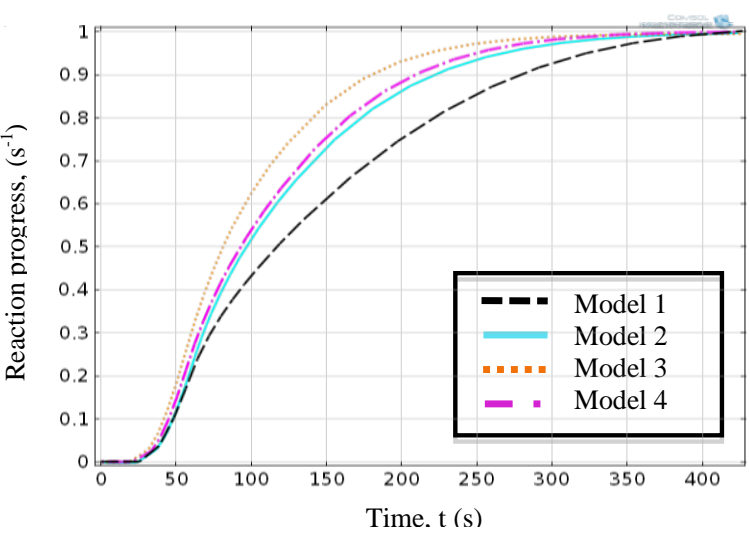

(b)

Fig. 6. (a) Reaction rate distribution at 300s: (i) Model 1, (ii) Model 2, (iii) Model 3, and (iv) Model 4, (b) Graph of reaction progress for each prototype over time.

\section{Conclusions}

Heat exchanger is one of the most crucial parts in solid-state hydrogen storage system which determines the efficiency of the system apart from the volumetric and gravimetric capacity of the system. In this paper, three new prototypes of heat exchanger plates are designed and the heat transfer efficiency of each prototype is simulated using COMSOL Multiphysics. From the results, hydriding reaction occurs faster with the addition of coolant tubes and reconstruction of plate fins in terms of number, shape and thickness. Apart from increasing the dissipation efficiency, the weight of the system must be kept low and therefore, the total space area occupied by the heat exchanger is reduced by $19.5 \%$ from the previous model. From this two-dimensional simulation, a clearer comparison of heat dissipation efficiency can be seen within different types of heat exchanger designs. 


\section{References}

[1] Visaria M, Mudawar I, Pourpoint T, Kumar S. Study of heat transfer and kinetics parameters influencing the design of heat exchangers for hydrogen storage using high-pressure metal hydrides. International Journal of Heat and Mass Transfer, 2010; 53(9):2229-2239.

[2] DOE, Fuel Cell Technologies Office Multi-Year Research, Development and Demonstration Plan (2012). Technical plan: Hydrogen storage. [Online]. Available: http://www1.eere.energy.gov/hydrogenandfuelcells/mypp/pdfs/storage.pdf

[3] Visaria M, Mudawar I, Pourpoint T. Enhanced heat exchanger design for hydrogen storage using high-pressure metal hydride: Part 1. Design methodology and computational results. International Journal of Heat and Mass Transfer, 2011; 54(1-3):413423.

[4] Mohan G, Maiya PM, Murthy SS. The performance simulation of air-cooled hydrogen storage device with plate fins. International Journal of Low-Carbon Technologies, 2010; 5(1):25-34.

[5] Botzung M, Chaudourne S, Gillia O, Perret C, Latroche M, Percheron-Guegan A, Philippe M. Simulation and experimental validation of a hydrogen storage tank with metal hydrides. International Journal of Hydrogen Energy, 2008; 33(1):98-104.

[6] Dhaou H, Souahlia A, Mellouli S, Askri F, Jemni A, Nasrallah SB. Experimental study of a metal hydride vessel based on a finned spiral heat exchanger. International Journal of Hydrogen Energy, 2010; 35(4):1674-1680.

[7] Lozano GA, Na Ranong C, Bellosta von Colbe JM, Bormann R, Hapke J, Fieg G, Klassen T, Dornheim M. Optimization of hydrogen storage tubular tanks based on light weight hydrides. International Journal of Hydrogen Energy, 2012; 37(3):28252834.

[8] Hull JF, Himeda Y, Wang WH, Hashiguchi B, Periana R, Szalda DJ, Muckerman JT, Fujita E. Reversible hydrogen storage using $\mathrm{CO}_{2}$ and a proton-switchable iridium catalyst in aqueous media under mild temperatures and pressures. Nature Chemistry, New York: Macmillan; 2012; 4:383-388.

[9] Jemni A, Nasrallah SB. Study of two-dimensional heat and mass transfer during absorption in a metal-hydrogen reactor. International Journal of Hydrogen Energy, 1995; 20(1):43-52. 